\title{
Betonarme Bir Yapıda Geleneksel Yöntem ve Taban İzolatörü Kullanımının Karşılaştırmalı Analizi
}

\author{
Halil İbrahim Polat ${ }^{*}$ \\ 1 İstanbul, Türkiye (ORCID: 0000-0002-4369-4343)
}

(İlk Geliş Tarihi 12 Aralık 2018 ve Kabul Tarihi 22 Ocak 2019)

(DOI: 10.31590/ejosat.495856)

ATIF: Polat, H. İ., (2019). Betonarme Bir Yapıda Geleneksel Yöntem ve Taban İzolatörü Kullanımının Karşılaştırmalı Analizi. Avrupa Bilim ve Teknoloji Dergisi, (15), 43-54.

\section{Öz}

Taban izolasyonu, yapıların, deprem gibi yanal yüklere karşı mukavemetini arttırmaktan ziyade, bu yüklerin yapıya olan etkisini düşürmeye, yükün yönünü çevirmeye ya da sönümlemeye çalışan bir tür yapı elemanıdır. Bu tasarım yönteminde, temel üstündeki yapı bölümlerinin, temelden ayrı bir çalışma biçimi edinerek deprem dalgası esnasında, katlar arası rölatif yer değiştirmenin minimuma indirmesi amaçlanmaktadır. Bu makalede; çerçevelerden müteşekkil mevcut olan bir okul yapısı öncelikle geleneksel ankastre mesnetli temel sistemiyle çözümlenmiş, mod şekilleri bulunmuş, yapı periyotları elde edilmiştir. Bunun için öncelikle statik eşdeğer deprem yükü yöntemi kullanılarak deprem yükleri kat yükseklikleri boyunca dağıtılmış ve kapasite problemi yaşayan yapı elemanları bulunmuştur. Ardından, 1999 Marmara depreminin Düzce meteoroloji istasyonunda kaydedilmiş, 0,005 s. zaman aralığına sahip ivme kayıtları yansıtılarak lineer olmayan zaman tanım alanı yöntemiyle analizler tekrarlanmış ve her iki yöntemin mukayesesi yapılmıştır. İkinci aşamada söz konusu yapıya, kurşun çekirdekli kauçuk taban izolatörlerinin eklenmesiyle zaman tanım alanı metodu kullanılarak analiz gerçekleştirilmiştir. Böylece, klasik yöntem ile taban izolatörlü sistemin mod şekilleri ve değişen periyotları arasında kıyaslamalar yapılmış olup izolasyon sistemli yapının periyotlarında kayda değer bir artışı meydana geldiği, spektral ivmelerin ve yapıya gelen kesme kuvvetlerinin azaldığı gözlenerek, ilk durumda var olan kesit yetersizliklerinin ortadan kalktığı görülmüştür.

Anahtar Kelimeler: Taban İzolatörü, Zaman Tanım Alanı, Kurşun Çekirdekli Kauçuk İzolatör.

\section{Comparative Analysis of a Concrete Structure Constructed with Conventional Technique and with Base Isolation}

\begin{abstract}
Base isolation is a type of building element that tries to reduce the effects of seismic lateral loads on the structure, rather than increasing the strength against these loads. In this design method, it is aimed to minimize the relative displacement between the floors during the earthquake wave by obtaining a separate working form of the building sections over the foundation. In this article; an existing school structure consisting of frames is firstly solved by the traditional built-in foundation based system, the mode shapes are found and the building periods are obtained. For this, earthquake loads are distributed along floor heights using the static equivalent earthquake load method, so structural elements with capacity problems are found. Then, 0,005 second time-history acceleration which is recorded at 1999 Marmara earthquake in Düzce meteorology station, is reflected and analyzes are repeated with the non-linear time-history method and the two methods are compared. In the second stage, the structure is analyzed by using the time-history method with the addition of lead-core rubber base isolators. Thus, the comparison of the mode shapes and the changing periods of the base isolator system with the conventional method is made. As a result, a significant increase in the period of the isolation system construction and the decrease of
\end{abstract}

\footnotetext{
* Sorumlu Yazar: İstanbul, Türkiye, ORCID: 0000-0002-4369-4343, halilibrahimpolat34@gmail.com
} 
the spectral accelerations and the shear forces coming to the structure are observed, and it is seen that the sectional deficiencies that existed in the first case are removed.

(Minimum 250 - Maximum of 400 words and content should be written in a way to include material, method, findings and results.)

Keywords: Base Isolation, Time History Method, Lead Core Rubber Isolation.

\section{Giriş}

Klasik yapı tasarımında, bir binaya sismik performans kazandırmak için başta kolon, kiriş, perde gibi taşıyıcı elemanların kesitlerini büyüterek ve yatay düzlemde sayısını çoğaltarak mukavemetini arttırmak, yapının kayda değer bir rijit davranış göstermesiyle sonuçlanmaktadır. Böyle bir taşıyıcı sistem seçimi dolayısıyla, yapıların daha fazla yatay kuvvet almasına ve üst katlardan tabana doğru geometrik artışlı bir kesme yüküne maruz kalmasına yol açmaktadır. Rijit cisim davranışı ve mukavemetin, temel nüans olarak alımlandığı bir taşıyıcı sistem yaklaşımında yapıya zeminden gelen sismik enerjinin tüketilmesi/sönümlenmesi için plastik mafsallaşma öngörülmektedir. Bu yaklaşım yapının hasar görmesini (minimal ölçeklerde ve kabul edilebilir derecede olsa dahi) kabul etmek anlamına gelmektedir. Son yıllarda plastik mafsallar ile yapısal hasarın nisbi olarak kabullenilmesi yoluyla sismik enerjinin tüketilmesi yaklaşımı yerine, sönüm elemanları vasıtasıyla söz konusu enerjinin tüketilmesi ve kat ivmeleri ile kat ötelemelerinin aynı anda düşürülmesi anlayışının taraftar bulduğu ve adına taban izolasyonu adı verilen bu sistemin uygulama sahasının genişlediği görülmektedir.

Deprem sırasında, yeryüzünde bir hareket meydana gelir. Bu hareket bir dalga şeklinde her doğrultuda yayılır ve bir yapıya eriştiğinde temellerini sallamaya başlar. Temeller de kendisine bağlı olan taşıyıcı sistemi sallar ve sistem elemanlarının kesitlerinde atalet kuvvetlerinin oluşturduğu etkiler meydana gelir. Yapı temelinin taşıyıcı sistemden ayrılarak titreşimin yapıya ulaşmasının önlenmesi, depremde taban yalıtımının ana fikrini oluşturur (Celep ve Kumbasar, 2004). Klasik ankastre temelli yapı tasarımında, yapıya nitelikli bir sismik performans kazandırmak adına taşıyıcı sistemi sağlamlaştırmak; yapının rijitliğini arttırmakta ve daha fazla kuvveti karşılaması ile sonuçlanmaktadır. Taban yalıtımı ise, yapının depreme karşı koyma kapasitesini arttırmaktan ziyade, onun depreme karşı tepkisini azaltma esasına odaklı bir tür depreme dayanıklı yapı tasarımı yaklaşımıdır. Yani, yapıların özellikle büyük magnitütlü depremler esnasında rijit cisim davranışı göstermesini ve yapısal zorlanmaların elastik sınırlar içinde kalmasını sağlamaktadır. Böylece deprem enerjisinin çok büyük bir kısmı yalıtım (izolasyon) seviyesinde sismik izolatör sistemi ve ek sönümleyici aygıtlar vasıtasıyla harcanmakta, deprem enerjisinin küçük bir bölümü yapıya iletilmektedir (Polat, 2007) (Şekil 1).

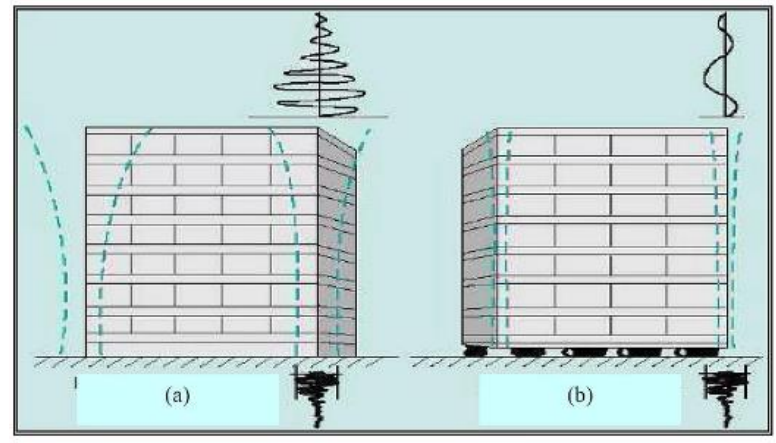

Şekil 1. Ankastre Tabanlı ve Sismik Yalıtımlı Yapıların Davranışı (Web 1, 2017)

Şekil 2'deki ivme-periyot değişim grafiğinde gösterildiği üzere, ankastre mesnetli yapıda \%0,5 - 1,0 - 2,0 - 5,0 ve \%10 sönüm oranlarında periyodların 1,0 s'nin altında olduğu buna karşın ivme değerlerinin bilhassa düşük sönüm oranlarında en yüksek mertebeye yükselmiş olduğu görülmektedir. Sismik izolatörün etkinleştirildiği durumda ise periyotların arttığı, ivme değerinin de arzu edilen düşük seviyelere çekildiği gözlemlenmektedir.

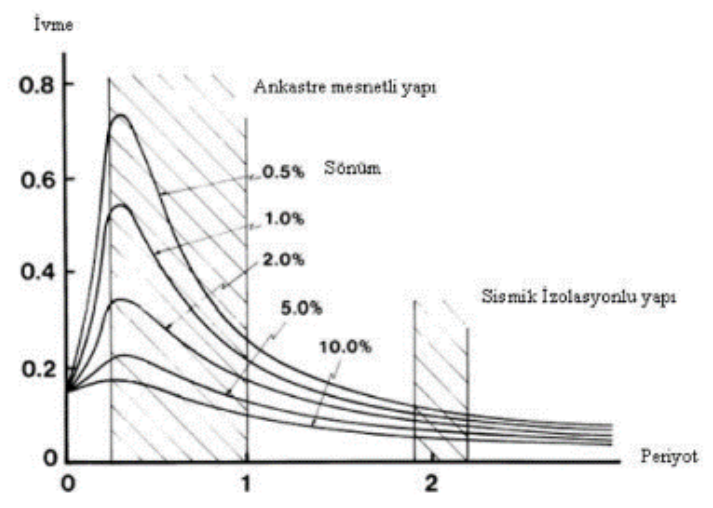

Şekil 2. Taban İzolasyonlu ve Ankastre Mesnetli Yapı Arasındaki İvme-periyot İlişkisi (Soyluk, 2010) 
Şekil 3'te ise ivme - periyot arasındaki ve deplasman - periyot ilişsisi irdelenmektedir. Buna göre Şekil 3'de ivme ile periyodun ters orantılı olduğu, periyot artışları ile ivme değerlerinin küçüldüğü buna karşın periyotların artışı ile birlikte kat yükseklikleri ile doğru orantılı olarak yer değiştirmenin de arttığı gözlemlenmektedir. Ancak bu yer değiştirme bilhassa yatay yönde olmakta ve katlar arası yer değiştirmenin minimal seviyede olduğu duruma işaret etmektedir.
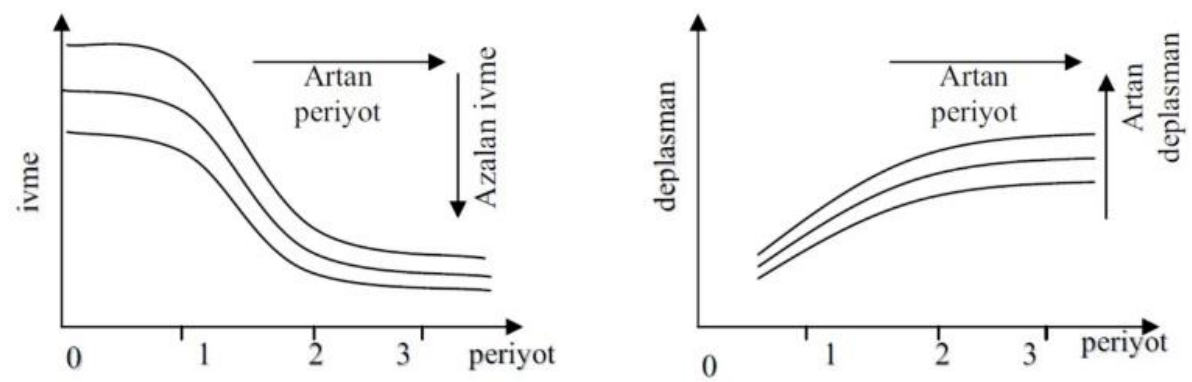

Şekil 3. Ivme-Periyot ve Deplasman-periyot Illişkisi (Web 2, 2017)

İzolasyon seviyesindeki olası büyük yer değiştirmelerin önlenmesi amacıyla yüksek sönümlü malzemelerin kullanılmasının faydalı olacağı düşünülmektedir. Bir yapının etkin rezonans periyodu genellikle 0,1 ile 1,0 saniye aralığındadır. Bu periyot aralığı aynı zamanda pek çok şiddetli depremin baskın periyot aralı̆̆ını da kapsar. Sismik taban yalıtımlı yapıların elastik birinci titreşim periyotlarının sabit tabanlı yapılara göre oldukça büyük olmasından dolayı Şekil 4 'te gösterildiği gibi elastik birinci titreşim periyotları büyütülerek, depremin yapılar için tehlikeli olan rezonans bölgesinden uzaklaşması sağlanmakta, böylece yer ivmelerinin yapı tarafindan büyütülmesi önlenmiş olmaktadır (Pekgökgöz, 2005).

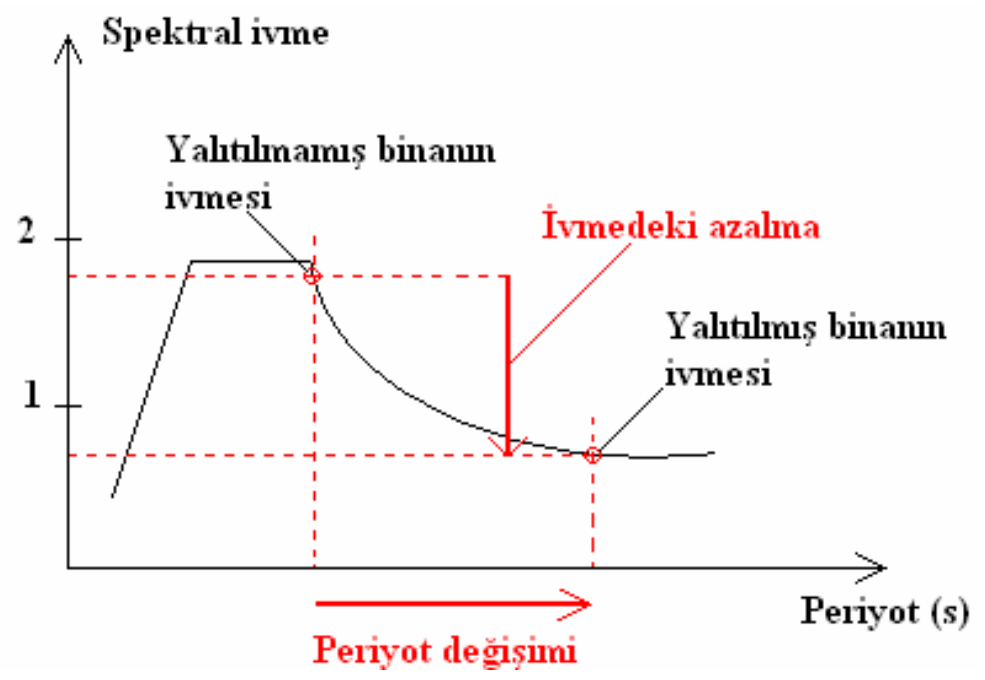

Şekil 4. Tipik Bir Tasarım Spektrumu

Eğer sismik izolasyonlu bir yapının doğal frekansı, eşleniği olan ankastre temelli yapının frekansına ve zemin hareketlerinin baskın frekansına kıyasla çok daha küçük olursa, yapının davranışı üstyapının hemen hemen rijit kaldığı ve sadece izolasyon sisteminin deformasyona uğradığı birinci dinamik modu tarafından belirlenir. Üstyapıda deformasyona neden olan daha yüksek modlar harekete katılmayacakları için bu yüksek modların içerdiği yüksek enerji de üstyapıya aktarılmayacaktır. Çoğu zaman depremlerin yatay bileşenleri düşey bileşenlerine göre daha şiddetlidir. Bundan dolayıdır ki, depreme dayanıklı yapı tasarımında kullanılan sismik izolatörler genellikle düşük yatay rijitlikle birlikte yüksek düssey rijitliğe sahip olacak şekilde tasarlanır. Yüksek düşey rijitlik ile düşük yatay rijitliğe sahip sismik izolatörlerle yalıtılmış bir yapı yatay yönde tek serbestlik dereceli sarkaç gibi davranır. Tek serbestlik dereceli sistemlerdeki kütle-rijitlik-frekans ilişkisi göz önünde bulundurularak, dikkatli bir tasarımla, belirli bir kütleye sahip temel izolasyonlu bir yapı, zemin hareketlerinin baskın frekanslarından yeterince uzak bir doğal frekansa sahip olacak şekilde tasarlanabilir (Aydın ve Ercan, 2004).

Sismik yalıtım elemanları, bodrum katın olmadığ yapılarda temel üstüne konulmakta olup bodrumlu yapılarda, kolon ve perde elemanlarının alt, orta veya üst kesitlerine yerleştirilmektedirler (Şekil 5-6). 


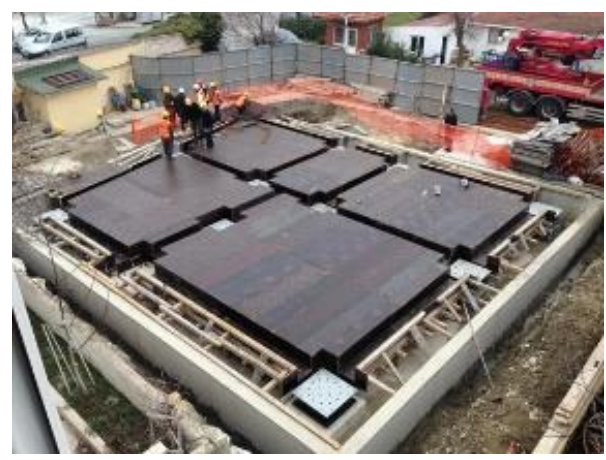

Şekil. 5. Temelde Yalıtım Sistemi (Web 3, 2017)

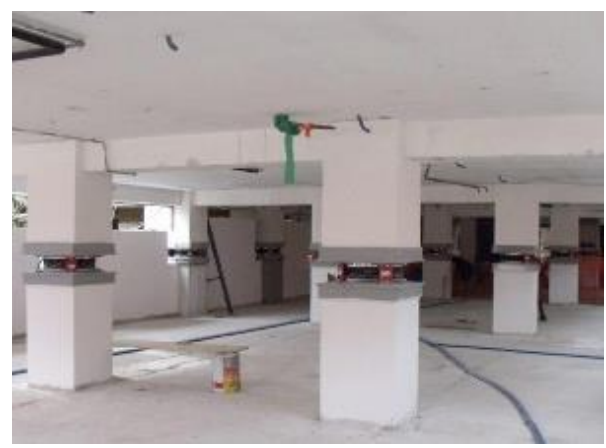

Şekil. 6. Kolon Orta Bölgesinde Yalıtım Sistemi (Web 4, 2017)

Sismik izolasyon uygulanmış yapı yatay yönde belli bir miktar deplasman yaptığından dolayı yapının etrafinda izolatörlerin yer değiştirme kapasitesi kadar boşluk olmalıdır. Örneğin; deprem derzine sahip olmayan bitişik nizam yapılarda, taban izolasyonu tekniğini uygulamak mümkün değildir. Çünkü bu tür yapılarda deprem enerjisini sönümleyecek boşluk olmadığı (yapının salınımına izin verilmediği) için izolasyon uygulamak da mümkün olamamaktadır. Depremler sırasında yapının dışarıyla bağlantısını sağlayan elemanların, elektrik, telefon, içme suyu, kanalizasyon, doğalgaz vs. bağlantıların yapının deprem hareketiyle yapacağı yer değiştirme sonrasında herhangi bir tahribat göstermemeleri gerektiğinden söz konusu tesisat bağlantıları da önceden kontrol edilmeli, eksikleri tamamlanmalı ve tesisat ekipmanlarının tamamının deplasman için bırakılan boşluk kadar esneme kapasitesine sahip olması gerekmektedir (Komodromos, 2000).

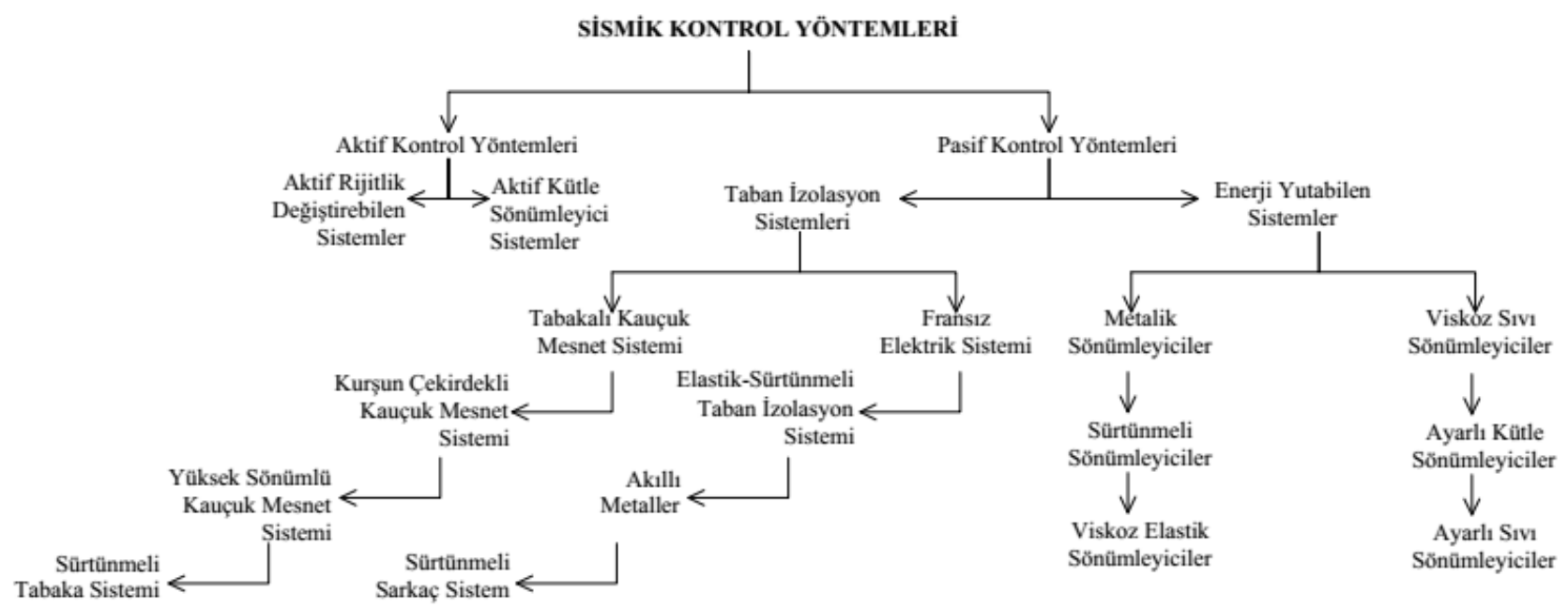

Şekil 7. Sismik Kontrol Yöntemleri (Robinson, 2000)

Aktif kontrol sistemleri, yapıya uygulanması düşünülen kontrol kuvvetinin deprem esnasında düzenlenmesi ilkesine dayanmaktadır. Pasif kontrol sistemleri ise bahse konu bölgede olası en büyük magnitüde sahip depremin meydana gelmesi ihtimali yörüngesinde tasarlanmaktadır (Şekil 7).

$\mathrm{Bu}$ çalışmada; kurşun çekirdekli kauçuk izolatör kullanılmış olduğundan, söz konusu bu izolatör türüne ait karakteristikler üzerine yoğunlaşılmıştır. Kurşun çekirdekli kauçuk izolatör, düşük sönüme sahip doğal kauçuk tabakaların çelik takviye plakaları yardımıyla birleştirilmesi ve ortasına silindir biçiminde kurşun çekirdeğin yerleştirilmesi ile meydana getirilmektedir. Kurşun malzemesi, akma 
noktasının altındaki şekil değiştirmelerde, formunu geçici olarak değiştirebilen kristalize bir malzemedir. Kauçuk ise yapısında var olan düzeltme kuvvetinin etkisiyle sistemin ilk haline dönmesini ve elastik özelliklerini korumasını sağlamaktadır. Kurşun çekirdek; çelik plakalar vasıtasıyla aktarılan kesme kuvvetleri etkisiyle plastik şekil değiştirmeye zorlanmaktadır. Bu bağlamda; kurşun çekirdekli kauçuk izolatörlerin enerji harcama mekanizması, kauçuk ile kurşunun elasto-plastik davranışa sahip olmaları ile ilgilidir.

\section{Materyal ve Metot}

\subsection{Geleneksel Ankastre Sistemli Bir Yapı Analizi}

Bu makalede; Etabs bilgisayar programı yardımıyla Şekil 8'deki planda gösterilen 3 katlı (zemin+2 normal kattan müteşekkil) $21,60 \times 14,35 \mathrm{~cm}$. boyutlarında, kat yüksekliği $3.00 \mathrm{~m}$. olan betonarme çerçeveli bir taşıyıcı sisteme sahip hali hazırda mevcut bir okul binasının analizleri yapılarak sonuçları değerlendirilmeye çalışılmıştır (Polat, 2007).

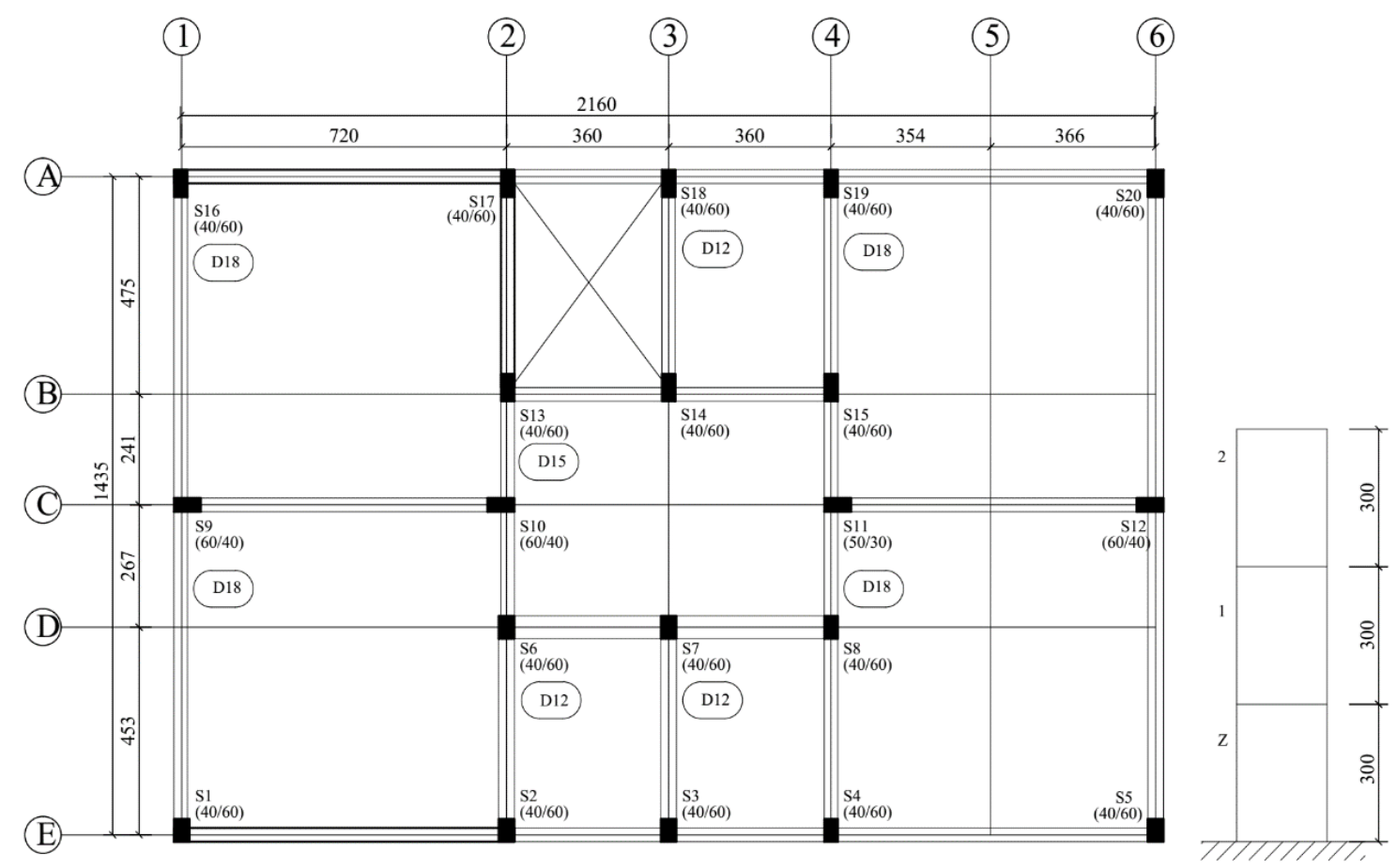

Şekil 8. Çerçeveden Oluşan Yapının Kat Planı

Yapıda; 30x50, 50x30, 40x60, 60x30 ve 60x40 cm olarak beş tip kolon kesiti bulunmaktadır (Tablo 1).

Tablo 1. Kolon Kesitleri

\begin{tabular}{ccc}
\hline Kat & $\begin{array}{c}\text { S1-S2-S3-S4-S5-S6-S7-S8-S13-S14- } \\
\text { S15-S16-S17-S18-S19-S20 }\end{array}$ & S9-S10-S11-S12 \\
\hline Zemin & $40 \times 60$ & $60 \times 40$ \\
\hline 1. Normal & $40 \times 60$ & $60 \times 30$ \\
\hline 2. Normal & $30 \times 50$ & $50 \times 30$ \\
\hline
\end{tabular}

Yapıdaki tüm kiriş boyutları 25x50 cm'dir. 12, 15 ve 18 cm'lik üç tip döşeme kesiti mevcuttur. Yapıda kullanılmış olan malzeme; beton için C20, çelik için ise BÇIII'tür.

Mevcut aks sistemine göre tasarlanan, tüm yapı elemanlarının kesit ve malzeme seçimleri yapılan, hareketli ve sabit yük dağılımları sağlanan, mesnetleri tanımlanan ve bu sayede Şekil 9'da gösterildiği gibi plan ve üç boyutta tasarımı tamamlanmış olan yapı, analize hazır hale getirilmiştir. 


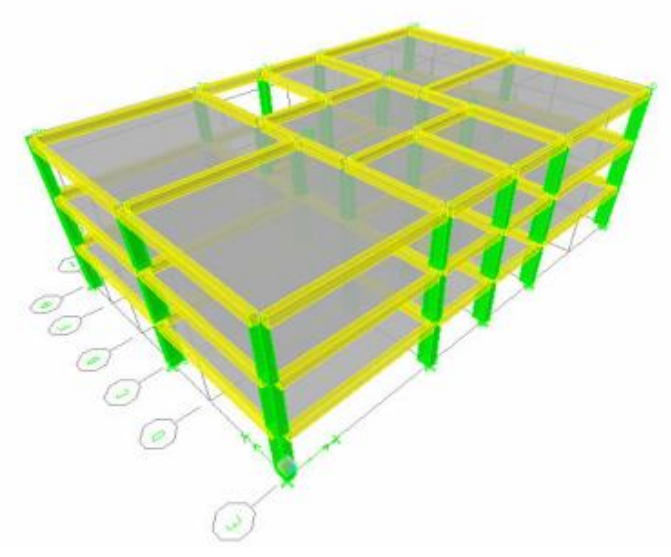

Şekil 9. Yapının Ü̧̧ Boyutlu Görünümü

Analiz sonucunda; yapının doğal titreşim periyotları belirlenmiştir. Buna göre; binanın 1. modu X doğrultusunda ve 0,5687 s. olarak hesap edilmiştir (Şekil 10).

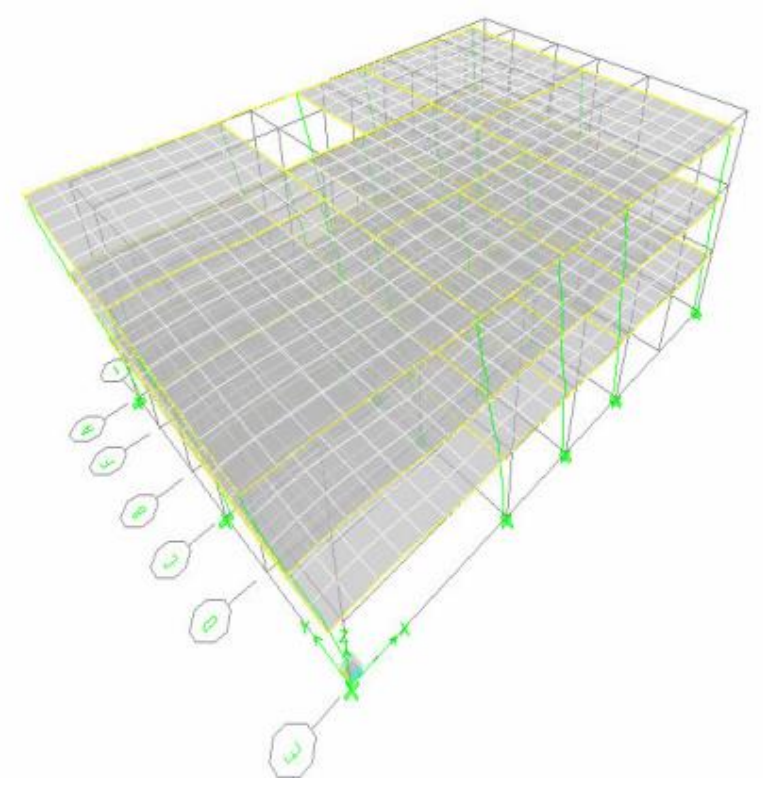

Şekil 10. 1. Mod Şekli $(T 1 X=0,5687$ s.

Yapının ikinci modu $Z$ yönünde ve 0,5625 s. , üçüncü modu ise $Y$ doğrultusunda 0,5003 s. olarak elde edilmiştir (Şekil 11 ve 12).

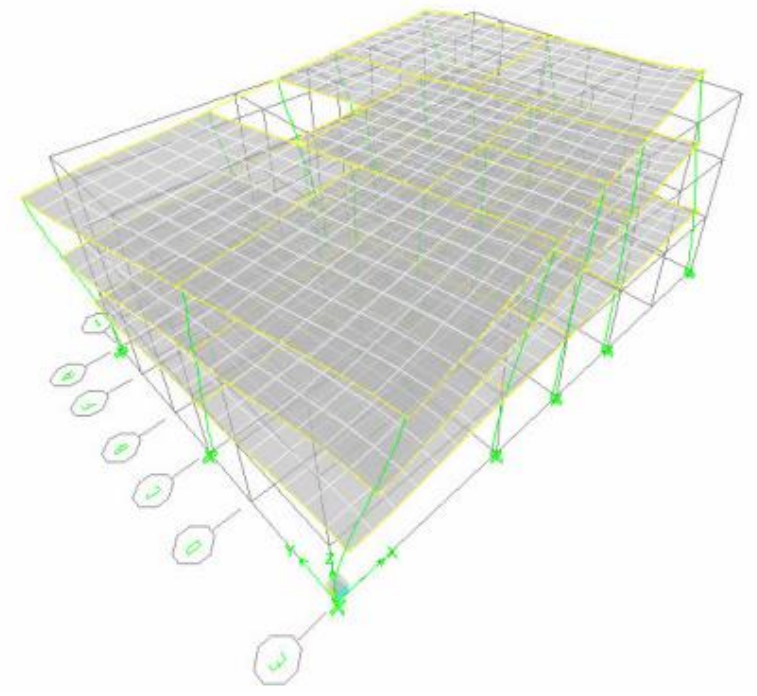

Şekil 11. 2. Mod Şekli (T1Z=0,5625 s.) 


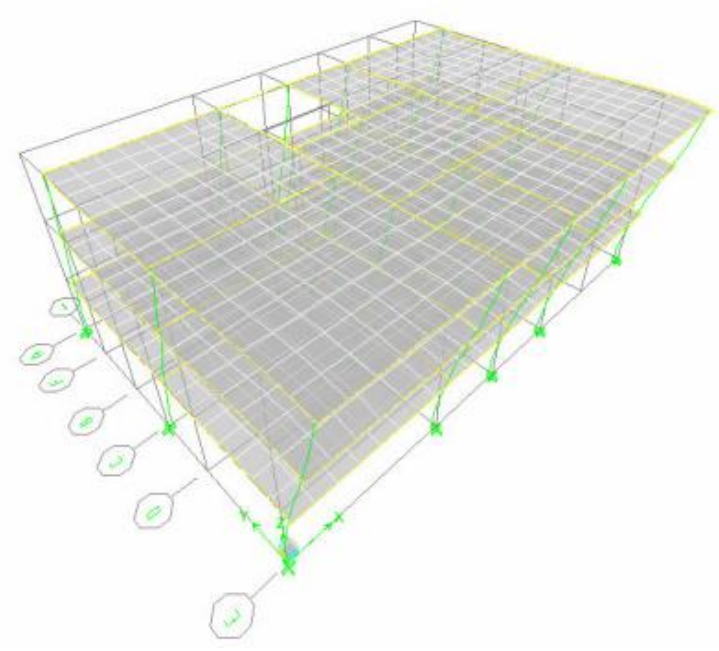

Şekil 12. 3. Mod Şekli (T1Y=0,5003 s.)

Mod şekilleri elde edildikten sonra; çerçeve sistem için doğrusal eşdeğer deprem yükü yöntemi analizine geçilmiş ve ardından 1999 Marmara depreminin Düzce meteoroloji istasyonunda kaydedilmiş doğu-batı ve kuzey-güney doğrultusu bileşenlerini içeren verilerden oluşan deprem ivme kaydı sisteme yansıtılarak zaman tanım alanında nonlineer analiz yapılmıştır. Bu iki analiz tamamlandıktan sonra, ankastre mesnetli sisteme taban izolatörü eklenerek aynı deprem ivme kaydı kullanılarak zaman tanım alanında sistemin yeniden çözümü sağlanmış ve her üç durumun mukayesesi (kesit yetersizlikleri, periyot, mod şekilleri, vb.) yapılmıştır. Bu işlemler aşağıda sirasıyla gösterilmektedir.

\subsubsection{Doğrusal eşdeğer deprem yükü yöntemi ile deprem analizi (mevcut sistem)}

Eşdeğer Deprem Yükü Yöntemi (EDYY) ile yatay deprem yükleri $\pm 0,05$ dış merkezliklerle kat hizalarına tanımlanmaktadır. Yapının deprem parametreleri aşağıdaki gibidir (DBYYHY, 2007):

- $\quad$ Etkin yer ivme katsayısı: A0=0,40 (1. derece deprem bölgesi)

- Yapı önem katsayısı: I=1,4 (Okul binasi)

- Spektrum karakteristik periyodu: $\mathrm{TA}=0,15, \mathrm{~TB}=0,60$ (Z3 zemin sınıfi)

- Taşıyıcı sistem davranış katsayısı: $\mathrm{R}=4$ (Süneklik düzeyi normal sistem)

Boyutlandırmada kullanılan toplam 21 adet yükleme kombinasyonu programa tanımlanmıştır. EDYY'nin parametreleri yansıtılarak yapılan analize göre yapıya ait kolon ve kirişlerin hiçbirinde kesit yetersizliğine rastlanılmamıştır. Şekil 13'de, EXTP yüklemesi altında yapının şekil değiştirmiş durumu görülmekte olup en büyük yerdeğiştirmenin olduğu 22 numaralı noktadaki deplasman ve dönmeler görülmektedir. Buna göre en büyük yer değiştirme X doğrultusunda 0,047525 m., en büyük dönme ise Y doğrultusunda 0,004525 m.' dir.

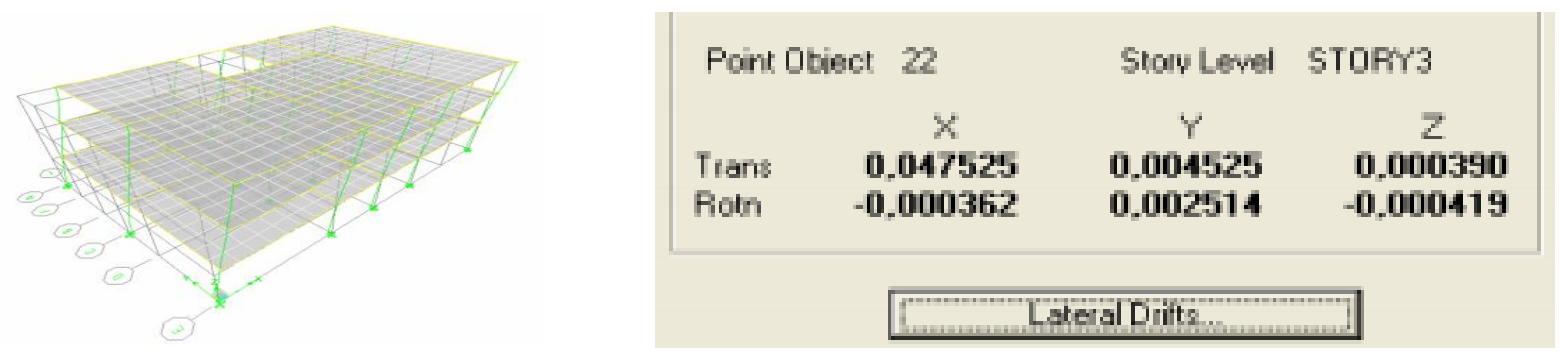

Şekil 13. EXTP Yüklemesi Altında Yapıdaki Şekil Değiştirme ve Noktasal Yer Değiştirme

\subsubsection{Doğrusal olmayan zaman tanım alanı ile deprem analizi (mevcut sistem)}

Mevcut sistem modeli için, malzeme karakteristiklerinde ve kesitlerde hiçbir değişiklik yapılmadan zaman tanım alanında (timehistory) çözümü yapılmıştır. 1999 Marmara depreminin Düzce meteoroloji istasyonunda kaydedilmiş, 0,005 s. zaman aralığına sahip, en büyük ivme değeri doğu-batı bileşeni için 3,73 m/s2, kuzey-güney bileşeni için ise 3,14 m/s2 ivme kayıtları kullanılmıştır (Şekil 14 ve 15). 


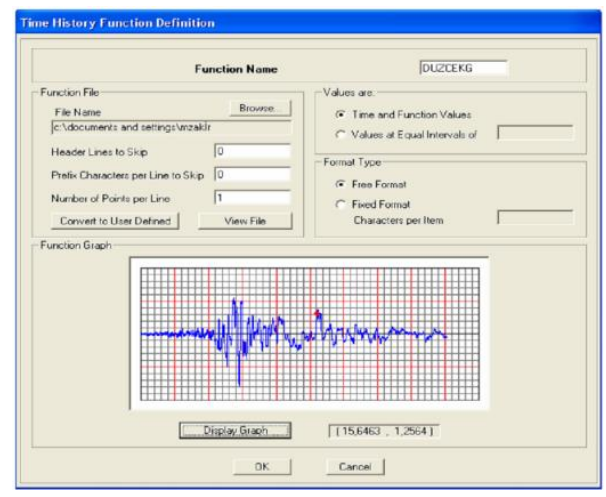

Şekil 14. Düzce Kuzey-Güney Bileşeni İvme Kaydı Grafiği

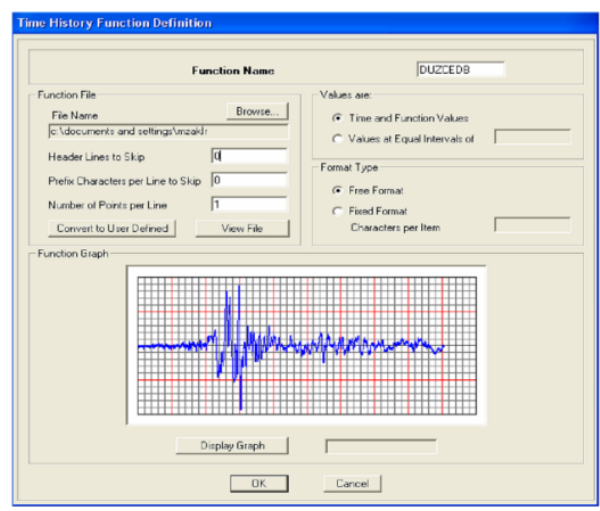

Şekil 15. Düzce Doğu-Batı Bileşeni İvme Kaydı Grafiği

Analiz sonuçlarına göre; maksimum donatı oranının sınırı aşıldığı yapı elemanları aşağıdaki gibidir (Tablo 2). Bu tabloya göre özellikle zemin katta tüm kolonlarda donatı sınırın aşıldığı ve gevrek kıvrılmanın yaşanabileceği ihtimali göz önünde bulundurulmalıdır.

Tablo 2. Maksimum Donatı Oranının Aşıldı ̆̆ Yapı Elemanları

(Reinforcing required exceeds maximum allowed)

\begin{tabular}{ccc}
\hline & Kolonlar & \\
\hline Zemin & Kat 1 & Kat 2 \\
\hline SZ01 & - & - \\
\hline SZ02 & S102 & S202 \\
\hline SZ03 & S103 & S203 \\
\hline SZ04 & S104 & S204 \\
\hline SZ05 & - & - \\
\hline SZ06 & S106 & S206 \\
\hline SZ07 & S107 & S207 \\
\hline SZ08 & S108 & S208 \\
\hline SZ09 & S109 & - \\
\hline SZ10 & S110 & S210 \\
\hline SZ11 & S111 & S211 \\
\hline SZ12 & S112 & - \\
\hline SZ13 & S113 & S213 \\
\hline SZ14 & S114 & S214 \\
\hline SZ15 & S115 & S215 \\
\hline SZ16 & - & - \\
\hline SZ17 & S117 & S217 \\
\hline SZ18 & S118 & S218 \\
\hline SZ19 & S119 & S219 \\
\hline SZ20 & - & - \\
\hline
\end{tabular}

Kesme gerilmesinin maksimum sınırı aştığı yapı elemanları da aşağıda gösterilmiştir (Tablo 3). Burada; 3, 7, 14 ve 18 nolu kolonların en büyük kesme kuvvetlerini aldığı ve tüm katlar boyunca kesme gerilmelerinin maksimum gerilmeyi aştığı hesap edilmiştir. Kesme gerilmesinin düşey düzlemde kapasiteyi aşmadığı herhangi bir eleman bulunmamaktadır. 
Tablo 3. Kesme Gerilmesinin Maksimum Sınırı Aştı̆̆ Yapı Elemanları

(Shear stress exceeds maximum allowed)

\begin{tabular}{ccc}
\hline & Kolonlar & \\
\hline Kat 1 & Kat 2 & Kat 3 \\
\hline SZ03 & S103 & S203 \\
\hline- & S104 & - \\
\hline SZ07 & S106 & S206 \\
\hline- & S107 & S207 \\
\hline SZ09 & S108 & S208 \\
\hline SZ10 & - & - \\
\hline SZ11 & - & S210 \\
\hline SZ12 & - & S211 \\
\hline SZ14 & - & - \\
\hline- & S113 & S213 \\
\hline- & S114 & S214 \\
\hline SZ18 & S117 & S215 \\
\hline- & S118 & S218 \\
\hline & S119 & - \\
\hline
\end{tabular}

\section{Taban İzolatörlü Sistem Analizi}

Çerçevelerden müteşekkil mevcut okul binasının temel-kolon birleşim bölgesine taban izolatörü konulmasıyla analizler yenilenmiştir. Taban yalıtım malzemesi için Dynamic Isolation Systems, Inc. firması tarafından üretilmiş olan DIS B türü kurşun çekirdekli kauçuk izolatör kullanılmıştır. Bu izolatörün karakteristiği Tablo 4'deki gibidir.

Tablo 4. DIS B Türü İzolatörün Karakteristik Özellikleri

\begin{tabular}{|l|l|}
\hline İzolatör elemanın toplam ağırlı̆̆ı & $8.3404 \mathrm{kN}$ \\
\hline Düşey yön için etkili rijitlik & $2.468 .654,085 \mathrm{kN} / \mathrm{m}$ (lineer) \\
\hline Yatay yön için etkili rijitlik & $1.180,926 \mathrm{kN} / \mathrm{m}$ (lineer) \\
\hline Yatay yön için etkili rijitlik & $6.808,12 \mathrm{kN} / \mathrm{m}$ (nonlineer) \\
\hline Akma dayanımı & $127,03 \mathrm{kN}$ \\
\hline Akma sonrası rijitliğin akma öncesi rijitliğe oranı & 0,1 \\
\hline
\end{tabular}

İzolatörün lineer ve nonlineer sönüm, akma, rijitlik değerlerinin atama işlemi Etabs programı yardımıyla Şekil 16'daki gibi yapılmış ve analize geçilmiştir (Özmen vd., 2005).

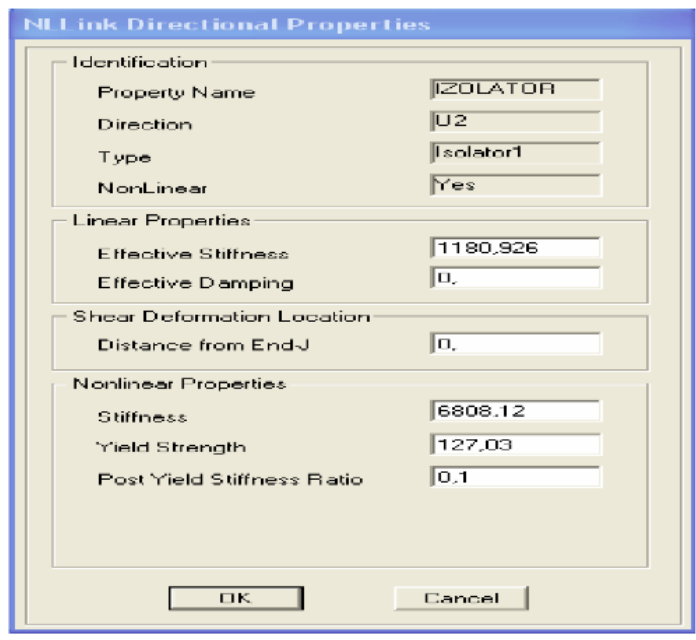

Şekil 16. DIS B Türü İzolatör Karakteristikleri Atama Ekranı

Analizler sonucunda; izolatörlü yapının doğal titreşim periyotları belirlenmiştir. Buna göre; binanın 1. modu Z doğrultusunda (burulma yönü) ve 1,7108 s. olarak hesap edilmiştir (Şekil 17). 


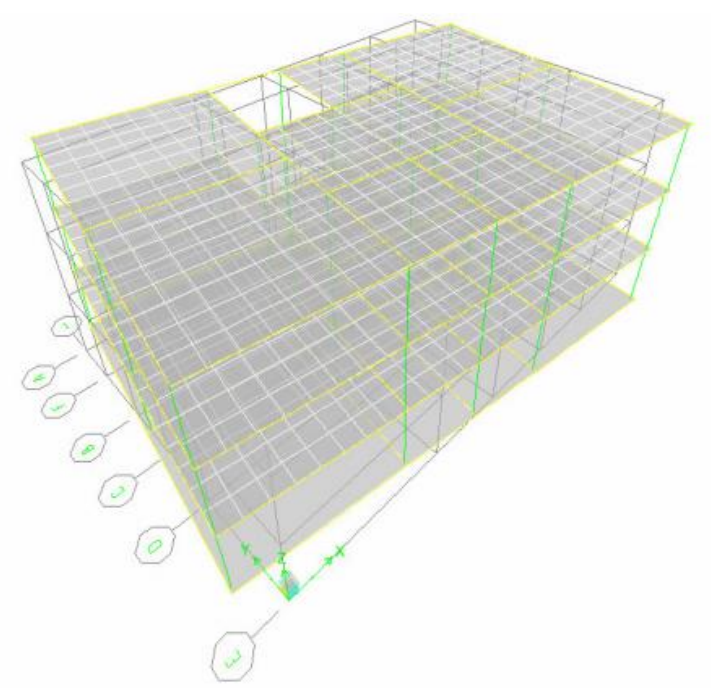

Şekil 17. İzolatörlü Sistemin 1. Mod Şekli (T1Z=1,7108 s.)

İkinci modu X doğrultusunda ve 1,6971 s., üçüncü modu ise Y doğrultusunda 1,6810 s. olarak hesaplanmıştır (Şekil 18 ve 19).

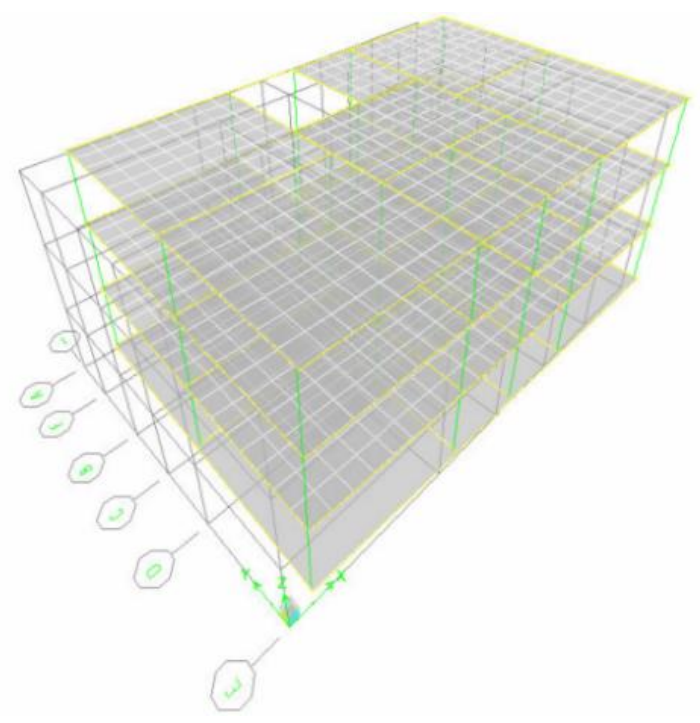

Şekil 18. İzolatörlü Sistemin 2. Mod Şekli (T1X=1,6971s.)

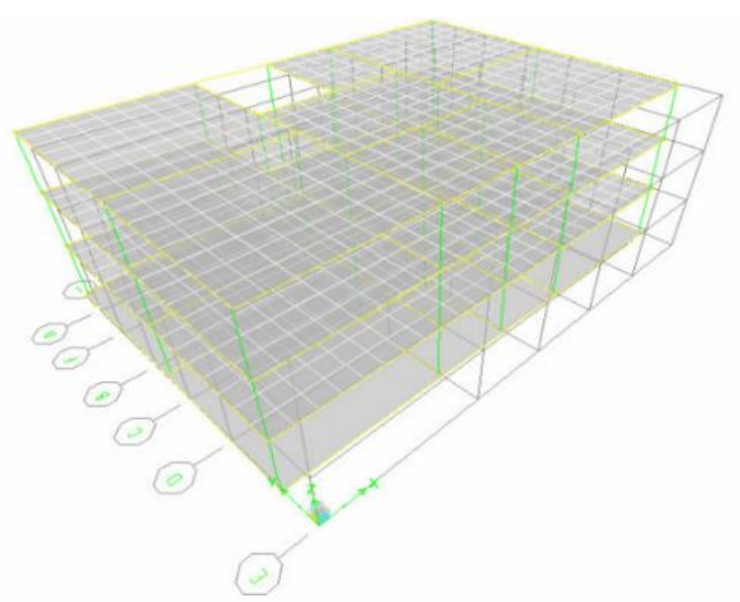

Şekil 19. İzolatörlü Sistemin 3. Mod Şekli (T1Y=1,6810s.)

Taban izolatörü atanmış mevcut sistemin; nonlineer zaman tanım alanında (time-history) çözümü gerçekleştirilmiştir. Şekil 14 ve 15 'deki ivme kayıtları baz alınarak yapılan analiz sonucunda ise mevcut durumun aksine maksimum donatı sınırını aşan yapı elemanlarının kalmadığı, kesme gerilme kontrollerin sağlandığı, tüm kesitlerin yeterli olduğu, herhangi bir kapasite sorununa 
rastlanmadığı görülmüştür. Klasik analizin 1. periyodu X doğrultusunda ve 0,5687 s. iken taban izolatörlü sistemin 1 . periyodu ise $Z$ (burulma yönü) doğrultusunda ve 1,7108 s. olarak elde edilmiştir.

\section{Sonuç ve Değerlendirme}

Çerçevelerden oluşan mevcut bir sistemin analizleri yapılmış, mod şekilleri ve periyotları belirlenmiş olup eşdeğer deprem yükü ve zaman tanım alanında deprem hesapları gerçekleştirilmiştir. Analiz sonuçlarına göre lineer olmayan zaman tanım alanı yöntemi kullanıldığında kesit yetersizliğin EDYY'ye oranla daha fazla olduğu görülmüştür. Bu nedenle taban izolasyonu uygulaması zaman tanım alanı yöntemi esas alınarak yapılmıştır. Böylece, DIS B türü kurşun çekirdekli kauçuk izolatörün atanmasıyla analizler yenilenmiş ve Tablo 5'de gösterildiği gibi mukayeseler yapılmıştır. Buna göre; taban yalıtımı uygulaması kullanılarak doğal periyotların ankastre mesnetli sisteme nazaran her üç doğrultu için yaklaşık 3 ile 4 kat arası arttığı görülmüştür. Bunun sonucu olarak taban yalıtımlı sistemde spektral ivmeler düşmüş, etkitilen deprem kaydı esnasında yapıya gelen kesme kuvvetlerinde azalma görülmüştür. Ayrıca yansıtılan deprem sırasında yapıda katlar arasında çok küçük ötelenme olduğundan rijit cisim davranışı görülmüş, şekil değiştirmeler özellikle izolatör seviyesinde kalmıştır.

Tablo 5. Periyotların Karşılaştırılması (Birim: saniye)

\begin{tabular}{|c|c|c|c|}
\hline \multicolumn{4}{|l|}{ Çerçeve Sistem } \\
\hline \multirow[b]{2}{*}{ Ankastre mesnetli sistem } & $T_{1 x}$ & $T_{1 y}$ & $T_{1 z}$ \\
\hline & 0.5687 & 0.5003 & 0.5625 \\
\hline Taban izolatörlü sistem & 1.6971 & 1.6810 & 1.7108 \\
\hline
\end{tabular}

Meydana getirilmiş olan sistemle ilgili olarak yapılan analizler sonucu Tablo 6 ve Tablo 7'de bir araya getirilmiştir. Buna göre; klasik ankastre mesnetli sistemin EDYY ile çözümünde yaşanmamış olan kapasite sorunları, nonlineer zaman tanım alanı yönteminin kullanılmasıyla ortaya çıkmış neredeyse bütün kolon kesitlerinde maksimum donatı oranının aşıldığı ve gevrek kırılma tehlikesinin olduğu görülmüştür. Ayrıca; ankastre mesnetli sistemde kesme kuvvetinin tüm düşey elemanlarda maksimum sınırın üzerinde bir gerilmeye sebep olarak kapasite sorunu yaratmasıyla birlikte yapıya taban izolatörü atanarak kapasite sorununun aşıldığı görülmüştür.

Tablo 6. Karşılaştırmalı Kapasite Tablosu

\begin{tabular}{|c|c|c|c|c|c|c|c|c|}
\hline \multicolumn{9}{|c|}{ Maksimum donatı oranının aşıldığı yapı elemanları } \\
\hline \multicolumn{3}{|c|}{$\begin{array}{c}\text { Ankastre mesnetli eşdeğer } \\
\text { deprem yükü yöntemi ile } \\
\text { çözümde }\end{array}$} & \multicolumn{3}{|c|}{$\begin{array}{l}\text { Ankastre mesnetli zaman tanım } \\
\text { alanı yöntemi ile çözümde }\end{array}$} & \multicolumn{3}{|c|}{$\begin{array}{l}\text { Taban izolatörlü zaman tanım } \\
\text { alanı yöntemi ile çözümde }\end{array}$} \\
\hline Kat 1 & Kat 2 & Kat 3 & Kat 1 & Kat 2 & Kat 3 & Kat 1 & Kat 2 & Kat 3 \\
\hline- & - & - & SZ01 & - & - & - & - & - \\
\hline- & - & - & SZ02 & S102 & S202 & - & - & - \\
\hline- & - & - & SZ03 & S103 & S203 & - & - & - \\
\hline- & - & - & SZ04 & $\mathrm{S} 104$ & S204 & - & - & - \\
\hline- & - & - & SZ05 & - & - & - & - & - \\
\hline- & - & - & SZ06 & S106 & S206 & - & - & - \\
\hline- & - & - & SZ07 & S107 & S207 & - & - & - \\
\hline- & - & - & SZ08 & S108 & S208 & - & - & - \\
\hline- & - & - & SZ09 & S109 & - & - & - & - \\
\hline- & - & - & SZ10 & $\mathrm{S} 110$ & S210 & - & - & - \\
\hline- & - & - & SZ11 & S111 & S211 & - & - & - \\
\hline- & - & - & SZ12 & S112 & - & - & - & - \\
\hline- & - & - & SZ13 & $\mathrm{S} 113$ & $\mathrm{~S} 213$ & - & - & - \\
\hline- & - & - & SZ14 & S114 & S214 & - & - & - \\
\hline- & - & - & SZ15 & S115 & S215 & - & - & - \\
\hline- & - & - & SZ16 & - & - & - & - & - \\
\hline- & - & - & SZ17 & S117 & S217 & - & - & - \\
\hline- & - & - & SZ18 & S118 & S218 & - & - & - \\
\hline- & - & - & SZ19 & S119 & S219 & - & - & - \\
\hline- & - & - & SZ20 & - & - & - & - & - \\
\hline
\end{tabular}


Tablo 7. Karşılaştırmalı Kapasite Tablosu

\begin{tabular}{|c|c|c|c|c|c|c|c|c|}
\hline \multicolumn{7}{|c|}{ Kesme gerilmesinin maksimum sınırı aştı̆̆ yapı elemanları } \\
\hline $\begin{array}{c}\text { Ankastre mesnetli eşdeğer } \\
\text { deprem yükü yöntemi ile } \\
\text { cözümde }\end{array}$ & \multicolumn{2}{c|}{$\begin{array}{c}\text { Ankastre mesnetli zaman tanım } \\
\text { alanı yöntemi ile çözümde }\end{array}$} & \multicolumn{2}{c|}{$\begin{array}{c}\text { Taban izolatörlü zaman tanım } \\
\text { alanı yöntemi ile çözümde }\end{array}$} \\
\hline Kat 1 & Kat 2 & Kat 3 & Kat 1 & Kat 2 & Kat 3 & Kat 1 & Kat 2 & Kat 3 \\
\hline- & - & - & SZ03 & S103 & S203 & - & - & - \\
\hline- & - & - & - & S104 & - & - & - & - \\
\hline- & - & - & - & S106 & S206 & - & - & - \\
\hline- & - & - & SZ07 & S107 & S207 & - & - & - \\
\hline- & - & - & - & S108 & S208 & - & - & - \\
\hline- & - & - & SZ09 & - & - & - & - & - \\
\hline- & - & - & SZ10 & - & S210 & - & - & - \\
\hline- & - & - & SZ11 & - & S211 & - & - & - \\
\hline- & - & - & SZ12 & - & - & - & - & - \\
\hline- & - & - & - & S113 & S213 & - & - & - \\
\hline- & - & - & SZ14 & S114 & S214 & - & - & - \\
\hline- & - & - & - & S115 & S215 & - & - & - \\
\hline- & - & - & - & S117 & - & - & - & - \\
\hline- & - & - & SZ18 & S118 & S218 & - & - & - \\
\hline- & - & - & - & S119 & - & - & - & - \\
\hline
\end{tabular}

\section{Kaynakça}

Aydın, H. ve Ercan, E. 2004. Yapısal Kontrol Sistemleri. TMMOB İnşaat Mühendisleri Odası İzmir Şubesi Haber Bülteni, İzmir, 118 , 28-32.

Celep, Z. ve Kumbasar. N. 2004. Deprem Mühendisliğine Giriş ve Depreme Dayanıklı Yapı Tasarımı. Beta Dağıtım, İstanbul.

DBYYHY - 2000. Deprem Bölgelerinde Yapılacak Yapılar Hakkında Yönetmelik. Bayındırlık ve İskân Bakanlığı, Ankara.

Komodromos, P. 2000. Seismic Isolation For Earthquake- Resistant Structures. Witpress, 10-30, 62-85, 98-109, Boston.

Özmen, G., Orakdöğen E. ve Darılmaz K. 2005. Örneklerle ETABS. Birsen Dağıtım, İstanbul.

Pekgökgöz, R. 2005. Deprem Yükleri Altındaki Yapı Davranışının Yarı-Aktif Akışkanlı Sönümleyiciler ve Sismik Taban Yalıtım Sistemleri Kullanılarak Bulanık Mantık Yöntemi ile Kontrolü. İstanbul Teknik Üniversitesi, Fen Bilimleri Enstitüsü, Doktora Tezi, İstanbul.

Polat, H. İ. 2007. Perde-Çerçeve ve Çerçevelerden Oluşan Yapıların Taban İzolatörleri Kullanılarak Analizi ve Değerlendirilmesi. İstanbul Teknik Üniversitesi, Fen Bilimleri Enstitüsü, Yüksek Lisans Tezi, İstanbul.

Robinson, W. H. 2000. Seismic Isolation of Civil Buildings in New Zealand. Progress In Structural Engineering And Materials, 2: 328324.

Soyluk, A. 2010. Sismik Taban İzolatörü Kullanımının Mimari Tasarıma Etkisi. Gazi Üniversitesi, Fen Bilimleri Enstitüsü, Doktora Tezi, Ankara.

Web 1, (2017), http://www.artyapiproje.com/tabanizolasyonu, 14.05.2017.

Web 2, (2017), http://www.artyapiproje.com/tabanizolasyonu, 25.06.2017.

Web 3, (2017), http://www.ulusyapi.com/Urun.aspx?Sub=23, 23.02.2017.

Web 4, (2017), http://santiyedefteri.com/index.php/2015/07/16/deprem-izalatoru-nedir, 17.03.2017. 